\title{
Maternal and neonatal consequences in patients with severe preeclampsia and patients with HELLP syndrome: a comparative study
}

\begin{abstract}
Background: The (HELLP) syndrome is a severe health hazard in pregnancy described by elevated liver enzymes, low platelet count and hemolysis. It happens in 0.4 to $0.7 \%$ of all gestations and in $10-12 \%$ of cases with severe preeclampsia.

Patients and methods: The present study was a prospective observational study that was made at Department of Obstetrics and Gynecology, Kasr Al-Ainy University Hospital, Cairo University, from September 2018 - March 2019. It included One Hundred and Thirty pregnant women diagnosed with hypertension in the current pregnancy complicated with severe preeclampsia, or HELLP Syndrome associated with abdominal ascites, recruited from the attendees of the Obstetric Emergency Department. The study was approved by the local institutional review board of the Faculty of Medicine, Cairo University. All ladies signed an informed consent.
\end{abstract}

Results: There were statistically significant differences between the HELLP group and the severe preeclamptic group regarding maternal ICU admission and the need of multiple drugs to control the blood pressure being less in severe preeclampsia group.

The need for ICU admission was much higher in the HELLP group (43.1\%) compared to the severe preeclampsia group $(9.2 \%)$ showing statistical significance $(\mathrm{P}<0.001)$

Conclusion: Maternal and neonatal sicknesses are elevated between cases with HELLP syndrome. So, early diagnosis and definitive treatment can be made to enhance maternal and neonatal results.
Volume II Issue 4 - 2020

\author{
Ahmed SSA Rashwan \\ Department of Obstetrics and Gynecology, Kasr Al-Ainy faculty \\ of medicine, Cairo University, Egypt
}

Correspondence: Ahmed SSA Rashwan, Department of Obstetrics and Gynecology, Kasr Al-Ainy faculty of medicine, Cairo University, Egypt, Email ahmedrashwan198I@gmail.com

Received: July 19, 2020 | Published: July 27, 2020

\section{Introduction}

Hypertensive Disorders in Pregnancy (HDP) is the most prevalent maternal complication worldwide as it affects $7-10 \%$ of all gestations and it is correlated with a marked maternal and fetal morbidity and mortality. ${ }^{1,2}$

$10-15 \%$ of maternal deaths \& $20 \%$ of perinatal mortality are directly associated with pre-eclampsia and eclampsia in developing countries. ${ }^{3,4}$ Severe hypertension in pregnancy is a hypertensive emergency that requires urgent intervention. Risk reduction together with successful and safe clinical outcomes needs adequate treatment of major systolic and severe diastolic hypertension. ${ }^{5}$

Preeclampsia usually occurs in the last trimester of pregnancy and more commonly in primiparas. It is characterized by maternal endothelial dysfunction presenting clinically with hypertension and proteinuria, and results in hypercoagulable state and may lead to acute renal failure (ARF), pulmonary oedema and approximately $10 \%$ of woman with severe preeclampsia may develop elevated liver enzymes , hemolysis and low platelet count referred to as HELLP syndrome. ${ }^{6}$

In HELLP syndrome maternal mortality ranges from 1-3\% with cerebral hemorrhage being the most common autopsy finding, ${ }^{7,8}$ with fetal and neonatal mortality and morbidity rates ranging from $9-24 \%$ and usually caused by prematurity, placental abruption, intrauterine asphyxia. ${ }^{9}$

The aim of this work is to determine the maternal and neonatal outcome differences between patients suffering from severe preeclampsia and patients with HELLP syndrome.

\section{Patients and methods}

This prospective observational study was conducted at Department Of Obstetrics and Gynecology, Kasr Al-Ainy Hospital, Cairo University, from September 2018 to March 2019. It included One Hundred and Thirty pregnant women diagnosed with hypertension in the current pregnancy complicated with severe preeclampsia, or with HELLP Syndrome. Patients were recruited from the attendees of the Obstetric Emergency Department. The study was approved by the ethical committee of the Faculty of Medicine, Cairo University.

Inclusion criteria included maternal age between 18-35years, gestational age between $30-38$ weeks confirmed by a dependable date for the last menstruation and US before 20 weeks of gestation, singleton living fetus, uncomplicated elective cesarean delivery of fetus without any associated anesthetic problems and delivery conducted by senior obstetrician, anesthesiologist with attendance of senior neonatologist. The diagnosis of preeclampsia was based on the criteria of the American College of Obstetrics and Gynecologists. ${ }^{5}$ The criteria of severe preeclampsia are blood pressure above $160 / 110 \mathrm{mmHg}$, severe proteinuria $(\geq 3+$ in random samples or $\geq 5 \mathrm{gm} / 24$ hours, evidence of CNS dysfunction, epigastric pain, oliguria or creatinine $>1.5 \mathrm{mg} /$ $\mathrm{dL}$, pulmonary edema, eclampsia, oligohydramnios, or severe fetal growth restriction. ${ }^{5}$ HELLP syndrome was diagnosed by strict criteria of sibai by determining that all 3 of the following criteria were 
present; hemolysis (characteristic peripheral blood smear and serum lactate dehydrogenase $>600 \mu / 1$ or serum total bilirubin $\geq 1.2 \mathrm{mg} / \mathrm{dl}$ ), elevated liver enzymes (serum aspartate aminotransferase $\geq 70 \mu / 1$ ), and low platelets count $(<100,000$ cells $/ \mu \mathrm{l}) .{ }^{10}$

Exclusion criteria included known liver disease, maternal medical disorders rather than hypertension, fetal congenital anomalies, rupture of membranes, ante partum hemorrhage (placenta previa or accidental hemorrhage), maternal administration of respiratory depressants within 2 hours from the delivery of the fetus (e.g., opioid analgesic ), renal disorder, history of illicit drug use, or any associated inflammatory disease or sepsis.

Patients were classified into 2 groups; group A $(n=65)$ represent patients with severe preeclampsia and group $B(n=65)$ represent patients with HELLP syndrome. All patients were subjected to thorough history taking, general, abdominal, and local physical examination. Full investigations were done, including complete blood count, liver function tests, kidney function tests, test for proteinuria were done by dipstick method, and coagulation profile including (fibrinogen level, prothrombin time, activated partial thromboplastin time, and D dimer level).

Transabdominal obstetric ultrasound examination was performed using a Medison R7 machine (Medison Co, Seoul, South Korea) equipped with a $4-7 \mathrm{MHz}$ transabdominal probe for a full obstetric examination of fetus, placenta and fetal wellbeing. All patients underwent non emergent caesarean section by senior obstetrician of the same medical degree belonging to the same team using the same intra operative techniques. All labors were attended by an expert neonatologist.

Perinatal outcomes were collected as intrauterine fetal death (IUFD), fetal asphyxia, low birth weight, respiratory distress, need for admission to Neonatal ICU (NICU), and perinatal mortality. IUGR was defined as a birth weight below the $10^{\text {th }}$ percentile for sex and gestational age diagnosed by two sonography examinations two weeks apart. Neonatal birth weight was measured. The neonate was classified as small for gestational age (SGA) if the birth weight was below the $10^{\text {th }}$ centile for the gestational age. The perinatal outcome was documented as birth weight, gestational age at delivery, and APGAR scores.

\section{Statistical analysis}

All the collected data was revised for completeness and logical consistency. Pre-coded data was entered on the computer using Microsoft Office Excel Software Program 2010.Pre-coded data was then transferred and entered into the Statistical Package of Social Science Software program, version 21 (SPSS) to be statistically analyzed. For quantitative variables (Using Kolmogorov-Smirnov Z test) variables that were normally distributed, were described as mean and SD compared using independent sample T Test, where $p$ value is significant if less than 0.05 . While variables that were not normally distributed were described as median, IQR (interquartile range $25^{\text {th }}$ percentile- $75^{\text {th }}$ percentile) and compared using Mann Whitney U test, where $p$ value is significant if less than 0.05 . For qualitative variables, they were described as frequency and percentage and compared using Chi-square test where $p$ value is significant if less than 0.05 .

\section{Results}

The two groups were comparable as regards age and body mass index (BMI), about $50.8 \%$ of severe preeclampsia group were multigravida while in the HELLP group up to $72.3 \%$ of patients were multigravida which was statistically significant $\mathrm{p}=(0.019)$. Gestational age (GA) at birth was significantly different between the two groups with a median of 37 weeks in preeclampsia group and 35 weeks in the HELLP group $\mathrm{p}(0.004)$ as shown in Table 1.

Table I demographic data of the studied groups

\begin{tabular}{llllll}
\hline & \multicolumn{2}{l}{ Group (A) } & \multicolumn{2}{l}{ Group (B) } & P value \\
\cline { 2 - 4 } & \multicolumn{2}{l}{$\begin{array}{l}\text { Preeclampsia } \\
\text { group }\end{array}$} & HELLP group & \\
\hline Age mean \pm SD & 29.1 & \pm 6.76 & 30.9 & \pm 5.54 & $0.88^{*}$ \\
BMI mean \pm SD & 31.1 & \pm 4.02 & 30.7 & \pm 4.66 & $0.63^{*}$ \\
GA median (IQR) & 37 & $(35-38)$ & 35 & $(34-37)$ & $0.004^{* *}$ \\
Parity Primi & 32 & $49.20 \%$ & 18 & $27.70 \%$ & $0.019 * * *$ \\
Multi & 33 & $50.80 \%$ & 47 & $72.30 \%$ & \\
\hline
\end{tabular}

\section{*independent test \\ **Mann Whitney test \\ ***Chi Square test}

As regards maternal outcomes the need for ICU admission was much higher in HELLP group (43.1\%) compared to severe preeclampsia group $(9.2 \%)$ showing statistical significance. Significant difference was also found between the two groups as regards the number of drugs, and the average time needed to control blood pressure during the postpartum period with a median of $1 \mathrm{drug}$ in preeclampsia group and 2 drugs in HELLP group, with a median of (1 day) and (2 days) between severe preeclampsia and HELLP groups respectively (Table 2). Also ultrasound changes in HELLP group were more and wider $(56.9 \%)$ compared to severe preeclampsia group (43.1\%) varying from IUGR, oligohydramnios, fetal Doppler changes and presence of free fluid in hepatorenal space referring to presence of ascites which was statistically significant. The need for transfusion of blood products, renal dialysis, and mechanical ventilation was more in HELLP group compared to preeclampsia group but was statistically nonsignificant (Table 2).

Based on the perinatal outcomes analysis presented in table 3 , it was found that HELLP syndrome group had lower fetal bodyweight, worse APGAR scores than severe preeclampsia group showing statistical significance. Neonatal mortality, NICU admission, and requirement for mechanical ventilation or nasal oxygen also showed higher percentage in HELLP group.

Number of drugs was needed to control blood pressure of patients during post-partum period in the studied groups. With median of 1 drug in severe preeclampsia group with average combination of (1-2) drugs, while with median of 2 drugs in HELLP group with average combination of $(2-3)$ drugs $(\mathrm{P}<0.001)$.

Cases with HELLP syndrome showed intra peritoneal ascites of median $200 \mathrm{ml}(150-300)$, in contrast to cases with severe preeclampsia having minimal immeasurable amount of intra peritoneal fluid $(\mathrm{P}<0.001)$.

There were highly significant differences regarding neonatal outcomes with almost $27 \%$ perinatal death in the HELLP syndrome with ascites group. 
Table 2 Maternal outcomes of the studied groups

\begin{tabular}{|c|c|c|c|c|c|c|}
\hline & \multirow[b]{2}{*}{ Yes } & \multicolumn{2}{|c|}{$\begin{array}{l}\text { Group (A) } \\
\text { Preeclampsia group }\end{array}$} & \multicolumn{2}{|c|}{$\begin{array}{l}\text { Group (B) } \\
\text { HELLP group }\end{array}$} & \multirow[t]{2}{*}{ P value } \\
\hline \multirow{2}{*}{ ICU n (\%) } & & 6 & $9.20 \%$ & 28 & $43.10 \%$ & \\
\hline & No & 59 & $90.80 \%$ & 37 & $56.90 \%$ & $<0.001 *$ \\
\hline \multirow{2}{*}{$\begin{array}{l}\text { Mechanical ventilation } \\
\mathrm{n}(\%)\end{array}$} & Yes & I & $1.50 \%$ & 4 & $6.20 \%$ & \multirow{4}{*}{$0.36 *$} \\
\hline & No & 64 & $98.50 \%$ & 61 & $93.80 \%$ & \\
\hline \multirow{6}{*}{ Transfusion n(\%) } & Yes & 5 & $7.70 \%$ & 16 & $24.60 \%$ & \\
\hline & No & 60 & $92.30 \%$ & 49 & $75.40 \%$ & \\
\hline & Plasma & 0 & $0.00 \%$ & 1 & $1.50 \%$ & \multirow{4}{*}{$0.17^{*}$} \\
\hline & Platelets & 0 & $0.00 \%$ & 9 & $13.80 \%$ & \\
\hline & RBCS & 5 & $7.70 \%$ & 5 & $7.70 \%$ & \\
\hline & $\begin{array}{l}\text { RBCS and } \\
\text { plasma }\end{array}$ & 0 & $0.00 \%$ & 1 & $1.50 \%$ & \\
\hline \multirow{2}{*}{ Renal dialysis n(\%) } & Yes & 2 & $3.10 \%$ & 4 & $6.20 \%$ & \multirow{3}{*}{$0.68 *$} \\
\hline & No & 63 & $96.90 \%$ & 61 & $93.80 \%$ & \\
\hline \multirow{2}{*}{ Ultrasound changes $n(\%$} & $\begin{array}{l}\text { Normal } \\
\text { ultrasound }\end{array}$ & 46 & $70.80 \%$ & 28 & $43.10 \%$ & \\
\hline & $\begin{array}{l}\text { Abnormalities in } \\
\text { ultrasound }\end{array}$ & 19 & $29.20 \%$ & 37 & $56.90 \%$ & $0.002^{*}$ \\
\hline \multicolumn{4}{|l|}{ Median (IQR) } & $(I-2)$ & & $<0.001 * *$ \\
\hline \multicolumn{2}{|c|}{ Number of drugs used to control BI pressure } & I & $(I-2)$ & \multicolumn{2}{|l|}{$(2-3)$} & $<0.00 I^{* *}$ \\
\hline
\end{tabular}

*Chi Square test

**Mann Whitney test

Table 3 Perinatal outcomes of studied groups

\begin{tabular}{|c|c|c|c|c|c|c|}
\hline \multirow{2}{*}{\multicolumn{2}{|c|}{ Fetal weight in gms median (IQR) }} & \multicolumn{2}{|c|}{$\begin{array}{l}\text { Group }(\mathbf{A}) \\
\text { Preeclampsia group }\end{array}$} & \multicolumn{2}{|c|}{$\begin{array}{l}\text { Group (B) } \\
\text { HELLP group }\end{array}$} & \multirow{2}{*}{$\begin{array}{l}\text { P value } \\
<0.001 *\end{array}$} \\
\hline & & 2700 & $(2100-2300)$ & 2000 & $(1700-2500)$ & \\
\hline Apgar score Imin mediar & & 5 & $(3-6)$ & 3 & $(\mathrm{I}-4)$ & $<0.00 I^{*}$ \\
\hline \multicolumn{2}{|c|}{ Apgar score 5 min median (IQR) } & 7 & $(5-8)$ & 5 & $(3-6)$ & \\
\hline & Died & 7 & $10.80 \%$ & 18 & $27.70 \%$ & $<0.001 *$ \\
\hline \multirow[t]{4}{*}{ Neonatal outcome n(\%) } & Living with no need to ICU & 47 & $72.30 \%$ & 26 & $40.00 \%$ & \\
\hline & Living with need to ICU & II & $16.90 \%$ & 21 & $32,3 \%$ & \\
\hline & No need to support & 30 & $46.20 \%$ & II & $16.90 \%$ & \multirow{2}{*}{$0.001 * *$} \\
\hline & dead & 7 & $10.80 \%$ & 18 & $27.70 \%$ & \\
\hline \multirow{2}{*}{ Neonatal support n(\%) } & Nasal oxygen & 21 & $32.30 \%$ & 25 & $38.50 \%$ & \\
\hline & Artificial ventilation & 7 & $10.80 \%$ & II & $16.90 \%$ & $0.002 * *$ \\
\hline
\end{tabular}

*Mann Whitney U test

**Chi Square test

Citation: Rashwan ASSA. Maternal and neonatal consequences in patients with severe preeclampsia and patients with HELLP syndrome: a comparative study. Obstet Gynecol Int J. 2020; I I (4):247-25I. DOI: I0.15406/ogij.2020.II.005 I 8 
HELLP group cases showed high rate of neonatal mortality $(27.7 \%)$ vs. $(10.8 \%)$ of severe preeclampsia group.

$12.1 \%$ of living neonates from severe preeclampsia group needed mechanical ventilation with NICU admission and, 36.2\% needed nasal oxygynation with or without NICU admission. While $23.4 \%$ of those of HELLP group needed mechanical ventilation and $53.2 \%$ needed nasal oxygynation.

\section{Discussion}

In the present study there was no significant difference between the study groups as regards age and BMI. While the gestational age and multiparity showed statistical significance between the studied groups.

Mean gestational age (GA) at time of diagnosis and delivery for the severe preeclampsia group was 37 weeks with interval between (35-38) weeks of gestation, while mean gestational age for the HELLP group was 35 weeks of gestation with interval between (34-37) weeks of gestation, showing statistical significance with $\mathrm{P}=(0.004)$.

These results agree with a previous study by Gokhan et al, 2011 who reported GA at the time of delivery to be 34.4 weeks for severe preeclampsia group and 34 weeks for HELLP group which was statistically significant, ${ }^{11}$ also in our study $50.8 \%$ of patients with severe preeclampsia were multiparas compared to $72.3 \%$ in HELLP group which was statistically significant $(\mathrm{p}=0.019)$ which agrees with previous studies. ${ }^{11,12}$

Hypertensive Disorders in Pregnancy (HDP) is the most prevalent maternal complication worldwide as it affects $7-10 \%$ of all pregnancies and it is associated with a significant maternal and fetal morbidity and mortality. Perinatal morbidity and mortality usually result from intrauterine growth restriction (IUGR) due to uteroplacental insufficiency and complications related to prematurity. ${ }^{13}$

Maternal outcomes showed statistical significance between the two groups regarding IUC admission being higher in the HELLP group with p-value $(<0.001)$.

As regards the need for blood transfusion, in the severe preeclampsia group and HELLP group 5 patients (7.7\%) needed transfusion of packed RBCs, while in HELLP group other patients needed furthermore, 9 patients $(13.8 \%)$ needed platelets transfusion, 1patient $(1.5 \%)$ needed plasma transfusion, and $1(1.5 \%)$ needed packed $\mathrm{RBCs}$ with plasma transfusion $\mathrm{P}=(0.017)$.

As regards the ultrasound changes found during diagnosis in the emergency department, $56.9 \%$ of HELLP group showed ultrasound changes $\mathrm{P}=(0.002)$ (Table 4$)$.

There was also statistical significant difference regarding the time taken to control blood pressure, along with combination of drugs needed to control blood pressure postpartum between the two groups $\mathrm{P}=(0.001)$.

There was no statistical significance regarding need for mechanical ventilation, or the need for renal dialysis between the two groups $\mathrm{P}=(0.36) \&(0.68)$ respectively.

The only cure for preeclampsia is delivery of the placenta. Although delivery is always appropriate for the mother, it might not be the best for a very premature fetus. ${ }^{14}$
The timing of delivery is therefore guided by weighing the relative risks of preterm delivery to the fetus against the risks of continuing the pregnancy to the mother. ${ }^{15}$

Table 4 Items of Ultrasound changes found in studied groups

\begin{tabular}{lll}
\hline Item & $\begin{array}{l}\text { Severe } \\
\text { preeclampsia }\end{array}$ & $\begin{array}{l}\text { HELLP } \\
\text { syndrome }\end{array}$ \\
\hline Oligohydraminos & 8 & 8 \\
IUGR & 2 & 10 \\
Oligohydraminos+IUGR & 6 & 8 \\
Drained Liquor & - & 5 \\
Doppler changes & 1 & 1 \\
Doppler changes+Other factors & I & 5 \\
\hline
\end{tabular}

There is consensus that women with preeclampsia should be delivered if preeclampsia is 'severe' or gestational age is either prior to fetal viability or term. However, severe preeclampsia now warrants delivery regardless of gestational age. ${ }^{16}$

The mean birth weight of neonates related to HELLP women was $1.9 \pm 0.7 \mathrm{~kg}$. While in the non-HELLP group women was $2.2 \pm 0.6 \mathrm{Kg}$. The different in the mean birth weights between the two groups was statistically significant $(\mathrm{P}<0.05)$.

Reports of a significantly low 1-minute Apgar score in neonates of hypertensive ladies are common. Furthermore reports that 5-minute APGAR scores $<7$ is common finding in neonates with adverse outcome of preeclamptic mothers. These results advise the necessity for enough planning for neonatal resuscitation at the delivery in gestations associated with hypertensive conditions. ${ }^{17}$

$54.5 \%$ of neonates in HELLP group had an unusual perinatal consequence and $24.6 \%$ of neonates in Non HELLP group. Hence HELLP group is intensely correlated with abnormal perinatal consequences. 27\% suffered Intra Uterine Fetal Death (IFUD) in HELLP group and $7 \%$ among Non-HELLP group. So, IFUD is markedly related with HELLP syndrome $(\mathrm{P}<0.01)$.

In the present study, among the HELLP group $55.8 \%$ delivered by LN, $2.3 \%$ by forceps, $41.9 \%$ by LSCS. Among the Non-HELLP group $43.9 \%$ delivered by LN, $3.5 \%$ by forceps, $52.6 \%$ by LSCS. There was no significant association between the two groups.

\section{Conclusion}

Maternal and neonatal sicknesses are elevated among cases with HELLP syndrome. So, early diagnosis and definitive treatment can be made to enhance maternal and neonatal results.

\section{Acknowledgments}

None.

\section{Funding}

None.

\section{Conflicts of interest}

No conflict of interest. 


\section{References}

1. Steegers E, Von Dadelszen P, Duveko J, et al. Pre-eclampsia. The Lancet. 2010;376(9741):631-644.

2. Cantwell R, Clutton-Brock T, Cooper G, et al. Saving Mothers' Lives: Reviewing maternal deaths to make motherhood safer: 2006-2008. The eighth report of the confidential enquiries into maternal deaths in the United Kingdom. BJOG Int J Obstet Gynaecol. 2011;118 Suppl $1: 1-203$.

3. Carty DM, Delles C, Dominiczak AF. Preeclampsia and future maternal health. J Hypertens. 2010;28(7):1349-1355.

4. Nalini N, Singh A, Singh J, et al. Perinatal Outcome and pregnancy induced hypertension: a better prediction by Doppler wave form study. International Journal of Contemporary Medical Research. 2015;2(5):1300-1304.

5. American College of Obstetricians and Gynecologists. Hypertension in pregnancy. report of the American college of obstetricians and gynecologists' task force on hypertension in pregnancy. Obstet Gynecol. 2013;122(5):1122-1131.

6. Ellenson LH, Pirog EC. The female genital tract chapter 22. Robbins and cotran pathologic basis of disease. In: Kumar Abbas Fausto Aster Editor, 8th edn. Philadelphia: Saunders Elsevier; 2010:1017-1024.

7. Isler CM, Rinehart BK, Terrone DA, et al. Maternal mortality associated with HELLP (hemolysis, elevated liver enzymes, and low platelets) syndrome. Am J Obstet Gynecol. 1999;181(4):924-928.

8. Magann EF, Isler CM, Rinehart BK, et al. Maternal mortality associated with HELLP (hemolysis, elevated liver enzymes, and low platelets) syndrome. American journal of obstetrics and gynecology. 1999;181(4):924-928.
9. Rath W, Faridi AN. Dudenhausen JW. HELLP syndrome. Journal of Perinatal Medicine. 2000;28(4):249-260.

10. Sibai BM. The HELLP syndrome (hemolysis, elevated liver enzymes, and low platelets): much ado about nothing?. American journal of obstetrics and gynecology. 1990;162(2):311-316.

11. Gökhan Yıldırım, Kemal Güngördük, Halil Aslan, et al. Comparison of perinatal and maternal outcomes of severe preeclampsia, eclampsia, and HELLP syndrome. J Turk Ger Gynecol Assoc. 2011;12(2):90-96.

12. Bouzari Z, Firoozabadi S, Hasannasab B, et al. Maternal and neonatal outcomes in HELLP syndrome, partial HELLP syndrome and severe pre-eclampsia: Eleven years' experience of an obstetric center in the north of Iran. World Applied Sciences Journal. 2013;26:1459-1463.

13. Ferrazzani S, Luciano R, Garofalo S, et al. Neonatal outcome in hypertensive disorders of pregnancy. Early human development. 87. 2011;87(6):445-449.

14. Barton JR, Sibai BM. Biomarkers for prediction, risk stratification, and ruling out preeclampsia: what are the appropriate goals and objectives?. Am J Perinatol. 2017;34(4):415-418.

15. Rhodes A, Evans LE, Alhazzani W, et al. Surviving sepsis campaign: international guidelines for management of sepsis and septic shock: 2016. Intensive Care Med. 2017;43(3):304-377.

16. Magee LA, Pels A, Helewa M, et al Canadian hypertensive disorders of pregnancy (HDP) working group. Diagnosis, evaluation, and management of the hypertensive disorders of pregnancy. Pregnancy Hypertens. 2014;4(2):105-145.

17. Adu-Bonsaffoh K, Ntumy MY, Obed SA, et al. Perinatal outcomes of hypertensive disorders in pregnancy at a tertiary hospital in Ghana. BMC pregnancy and childbirth. 2017;17(1):388. 